\title{
The JGrass-NewAge system for forecasting and managing the hydrological budgets at the basin scale: models of flow generation and propagation/routing
}

\author{
G. Formetta ${ }^{1}$, R. Mantilla ${ }^{2}$, S. Franceschi ${ }^{3}$, A. Antonello ${ }^{3}$, and R. Rigon ${ }^{1}$ \\ ${ }^{1}$ University of Trento, 77 Mesiano St., Trento, 38123, Italy \\ ${ }^{2}$ The University of Iowa, C. Maxwell Stanley Hydraulics Laboratory, Iowa 52242-1585, USA \\ ${ }^{3}$ Hydrologis S.r.l., Bolzano, BZ, Italy
}

Received: 16 April 2011 - Published in Geosci. Model Dev. Discuss.: 29 April 2011

Revised: 20 September 2011 - Accepted: 31 October 2011 - Published: 4 November 2011

\begin{abstract}
This paper presents a discussion of the predictive capacity of the implementation of the semi-distributed hydrological modeling system JGrass-NewAge. This model focuses on the hydrological budgets of medium scale to large scale basins as the product of the processes at the hillslope scale with the interplay of the river network. The part of the modeling system presented here deals with the: (i) estimation of the space-time structure of precipitation, (ii) estimation of runoff production; (iii) aggregation and propagation of flows in channel; (v) estimation of evapotranspiration; (vi) automatic calibration of the discharge with the method of particle swarming.

The system is based on a hillslope-link geometrical partition of the landscape, combining raster and vectorial treatment of hillslope data with vector based tracking of flow in channels. Measured precipitation are spatially interpolated with the use of kriging. Runoff production at each channel link is estimated through a peculiar application of the Hymod model. Routing in channels uses an integrated flow equation and produces discharges at any link end, for any link in the river network. Evapotranspiration is estimated with an implementation of the Priestley-Taylor equation. The model system assembly is calibrated using the particle swarming algorithm. A two year simulation of hourly discharge of the Little Washita (OK, USA) basin is presented and discussed with the support of some classical indices of goodness of fit, and analysis of the residuals. A novelty with respect to traditional hydrological modeling is that each of the elements above, including the preprocessing and the analysis tools, is implemented as a software component, built upon Object Modelling System v3 and jgrasstools prescriptions, that can be cleanly switched in and out at run-time, rather than at
\end{abstract}

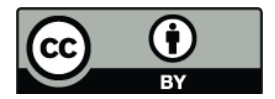

Correspondence to: G. Formetta

( formetta@ing.unitn.it) compiling time. The possibility of creating different modeling products by the connection of modules with or without the calibration tool, as for instance the case of the present modeling chain, reduces redundancy in programming, promotes collaborative work, enhances the productivity of researchers, and facilitates the search for the optimal modeling solution.

\section{Introduction}

Hydrological forecasting over time has focused on different issues. Determining the discharge of rivers during flood events has been a central topic for more than a century; firstly through the rational model of Mulvaney (1851), later through the use of instantaneous unit hydrograph models (Sherman, 1932; Dooge, 1959), and more recently including the geomorphological approach (i.e. GIUH; RodríguezIturbe and Valdés, 1979; Gupta and Waymire, 1980; Rosso, 1984; D'Odorico and Rigon, 2003). Even models of runoff generation such as Topmodel (Beven and Kirkby, 1979; Beven, 2001; Franchini et al., 1996) have been used mainly for this purpose.

Subsequently, however, the water resource and river management required the need to estimate a whole set of hydrological quantities such as discharge, evapotranspiration, and soil moisture, bringing very soon to the implementation of more comprehensive modeling systems, like the pioneering Stanford watershed model (Crawford and Linsley, 1966), the Sacramento model (e.g. Burnash et al., 1973), and the PRMS model (Leavesley et al., 1983). They were usually based on the idea of intercommunicating compartments (reservoirs), each representing a process domain, each one with its residence time. 
A short compendium of efforts is represented by the recent "Distributed Model Intercomparison Project", DMIP, (Reed et al., 2004), that revealed the variety of needs and approaches proposed by various researchers and agencies, and provided a first set of tentative comparison between hydrological models.

Besides the above mentioned examples, research and operational needs produced an even greater number of models, with varying degrees of complexity and simplifications. The two extremes are given by fully distributed models on the one hand and lumped models on the other (for recent reviews, see Kampf and Burges, 2007; Rigon et al., 2006; Beven, 2001). In the first class, the physics is modeled at grid (pixels) level using the fundamental laws of conservation of energy, mass, and momentum; in the second, the ruling equations are simplified in order to obtain some statistics of the hydrological budget without representing the full spatial variability of the processes. Simplifications were sometimes derived by solid arguments, and in this context a solid paradigm is offered by the theory of the geomorphological unit hydrograph (e.g. Rinaldo et al., 1991; Rigon et al., 2011), or by heuristic subjective arguments (e.g. Sivapalan et al., 2003).

In parallel to the development of the "physics", there was always a search for endowing the models of graphical interfaces, tools and database to treat input and output data: a necessary addition to improve researchers' productivity and to promote model utilization among technical end-users of governmental authorities, once the quality of the models was assessed.

The JGrass-NewAge was conceived as a system able to offer a graphical interface to models without extra programming burden (Antonello et al., 2011), and to reduce the gap between the production of new hydrological research and its deployment to stakeholders.

To achieve this result, after testing alternatives, the OMS3 infrastructure (http://oms.javaforge.com) was chosen, having found in its concepts of programming by components, which allows to test different modeling approaches by changing parts of a model at run-time (not at compiling time), a strategy both useful to research and to tailor modeling solutions to the requirement of a particular use-case.

Into JGrass-NewAge, besides the OMS3 framework capabilities, we integrated a full featured geographic information system (GIS), udig-jgrass (http://udig.refraction.net and http://www.jgrasstools.net). In fact the new udig Spatial toolbox is largely an outcome of the research presented in this paper. Spatial toolbox /OMS3 components are able to deal with spatial coverages and features, specified according to the standards of the Open GIS Consortium (OGC), and implemented by Geotools (http://www.geotools.org). Moreover, they work seamlessly in the GIS within a user interface that is automatically created from the metadata present in any component's appropriately programmed source code.
Therefore JGrass-NewAge users have the possibility to mix compatible model components, create their own runtime models, and prepare and visualize the results within the udig-jgrass GIS system.

This paper, however, does not present the core informatics that made this possible; rather it has the goal to demonstrate that the strategy adopted is effective in producing sound science. Therefore, we have linked some submodels into JGrass-NewAge, and with this paper we aim to demonstrate that this assemblage is able to reproduce at best the discharge in a catchment.

The model structured out of the JGrass-NewAge components was addressed to forecast the discharge at hourly time scale in any link inside a river network; to calculate the water budget at any point in a basin.

\section{Methods}

The JGrass-NewAge system is implemented in the udigJGrass GIS system, which is, in the present version, a compound of a GIS with vectorial and raster services embedded in the core distribution of the udig GIS, and various modeling components called jgrasstools (http://code.google.com/p/ jgrasstools/) that can be executed from within the udig Spatial toolbox. The tools include, besides JGrass-NewAge, a comprehensive set of models for analysis of topography, and other hydro-geomorphological modeling efforts like the SHALSTAB model (Dietrich et al., 1992 and Montgomery and Dietrich, 1994) and Peakflow (Rigon et al., 2011).

The JGrass-NewAge model, as linked for this paper, is composed by the elements enumerated in Table 1, which also includes the components dedicated to calibration. The table summarizes all the OMS3 components implemented, their data requirements, and their outputs. When linked the components are processed in sequence exchanging their data directly in computer memory without the need to exchange data by writing temporary files (David et al., 2010).

\subsection{Basin delineation}

The first step in building JGrass-NewAge is to find a suitable GIS representation of the watersheds. The model partitions the basin into hillslopes and channels (giving to the model a hillslope-link, HL, structure), where the hillslopes are the basic hydrologic units. It is at this scale that the energy and water mass budgets statistics are estimated. The channels are described as vector elements (features) that are topologically interconnected in a simple directed graph. This concept could be confused with the concept of hydrological runoff units (HRUs) promoted in Ross et al. (1979), Flügel (1995), and used, for instance in Krause (2002), and in Viviroli et al. (2009). Any HRU, however, is derived from the intersection of various classes of superimposed information layers, and are, therefore, clusters representing areas of the 
basin where similar hydrological behavior is expected. In JGrass-NewAge, on the other hand, the HL structure is derived from the watershed delineation (which is performed by other modeling components written according to the same OMS3), and represents the set of flow lines that converge to an outlet and/or to a cross section.

Thus HRUs can be seen as sub-partitions of the hillslope, and in JGrass-NewAge these sub-classes provide statistics models at hillslope (or small watershed) level, rather than single estimations of the hydrological quantities. These subpartitions (and the relative sub-parameterizations, when applicable) are process dependent, as, for instance, the hillslope HRUs for evapotranspiration could be different from the ones for snow modeling (not presented in this paper). For computational reasons, the partitioning of the area is not usually designed to identify all the physical hillslopes present in the system, but to define small watersheds with dimensions, in the current application, of $2-3 \mathrm{~km}^{2}$ on average. HRUs can be either treated as vectorial features, or rasters, according to convenience.

In the model any element of the river network is represented as a vectorial entity (OGC feature) connecting the hillslopes. The network can include, when present, anthropogenic infrastructures that regulate the flow regimes, and thus it is possible to simulate intakes, management of dams, artificial channels, and water abstractions due, for instance, to irrigation. The way in which all of these elements are implemented in the JGrass-NewAge system is built upon the definition of a topological hierarchy based on a modification of Pfafstetter's ordering scheme (Verdin and Verdin, 1999; de Jager and Vogt, 2010). In our implementation of Pfafstetter's hierarchy we removed the limit to four tributaries per stream, originally introduced to represent any river link with a decimal number, in order to partially cope with the needs of river basin and geography institutions which name tributaries, and establish their order, not on the basis of objective physiography but of history.

There are several methods to extract the river network: according to threshold on the contributing areas, a suitable product of slope and contributing area (Rodriguez-Iturbe and Rinaldo, 1997), curvatures (Pirotti and Tarolli, 2010), and the main ones are implemented in jgrasstools. Once the network is extracted, hillslopes are identified accordingly, as that part of the landscape that drains into a channel link following the gradients of topography. Finally the link are numbered according to Pfafstetter's method, and this numeration is used for driving the computation.

\subsection{Rainfall and other input data}

The second step is to implement suitable algorithms for spatially distributing the precipitation measured at ground level at meteorological station sites. The hydrological budgets estimation can be flawed from the beginning if the atmospheric forcings (i.e. spatial field time series of precipitation, air temperature, and solar and thermal radiation) are not properly accounted for. These variables have particular characteristics and levels of data availability that make it necessary to use a variety of procedures to develop spatial fields for each. However, to keep the modeling chain simple, we limit the present investigation to the use of simple kriging (Goovaerts, 1997), and a kriging detrended for the estimation of precipitation and for interpolating air temperatures. An internal component of the Kriging module provides, for each time step, the best theoretical semivariogram model able to fit the experimental one, chosen from the Gaussian, Exponential, Spheric and Linear models.

We used these techniques mainly because they can easily account for topographic and other features discussed for instance in Jarvis and Stuart (2001), where it was argued that modelers should be aware of the influence of many topographic characteristics besides elevation. Also Garen and Marks (2005) provides an insightful discussion of this topic with particular focus of the modeling of snow, which we do not replicate here.

Solar radiation was estimated implementing Corripio (2003) models which allow for simulating the incoming shortwave radiation according to topography inclination and aspect, and estimating shadowing and the angle of view, which reduces the portion of sky visible to from any point, and therefore the amount of radiation received, for instance, in a valley with respect to a site in the plain. Long wave radiation was estimated using air temperature as a proxy for the terrain and canopy temperatures, and using the Brutsaert (1975) and Brutsaert (2005) parametrizations which revealed to be effective in other works (e.g. Rigon et al., 2006).

\subsection{Runoff generation}

The third step was the choice of the runoff generation mechanism. While, in principle, a more physically based choice (built for instance on an estimation of the flow paths structure deduced from a detailed digital elevation model) was preferable, we opted to use a standard model already presented in literature. At the beginning, we were tempted by an appealing modeling effort by Duffy (1996). However, we later had to concede that its conceptual simplicity did not correspond to an easiness of application, since the parameter range provided in Duffy (1996) was not extensible to catchments with different soil type and soil hydraulic properties. Therefore, once the parameters that had been kept fixed in the original paper and the tunable parameters were considered all together in this case, calibrating them became simply a computationally overwhelming task. Hence, we decided to use the Hymod model (Moore, 1985 and Boyle, 2001), which is outlined below. The Hymod runoff component has only five parameters which can be automatically calibrated.

The Hymod model was not used for the whole catchment, providing instead the water storage and the streamflow for each time-step for any single hillslope. The rationale of using 
Table 1. OMS3 components used to constitute the JGrass-NewAge model. Where not specified, quantity in input or output must be intended as a spatial field for any instant of simulation time. "Measured" refers to a quantity that is measured at a meteorological station. Geomorphic features refer to the hillsslope and channel delineation, slope and aspect. The components, besides the specfied files received in input, include an appropriate set of parameter values.

\begin{tabular}{|c|c|c|}
\hline Inputs & Component & Output \\
\hline Measured Rainfall & KRIGING & Rainfall \\
\hline Measured Temperature & KRIGING & Temperature \\
\hline $\begin{array}{l}\text { Digital Elevation Model } \\
\text { Atmospheric parametes }\end{array}$ & CORRIPIO + BRUTSAERT & Radiation \\
\hline $\begin{array}{l}\text { Temperature } \\
\text { Radiation }\end{array}$ & PRIESTLEY-TAYLOR & Evapotranspiration \\
\hline $\begin{array}{l}\text { Rainfall } \\
\text { Evapotranspiration } \\
\text { Geomorphic features }\end{array}$ & HYMOD + ROUTING & $\begin{array}{l}\text { Streamflow at any } \\
\text { river network node }\end{array}$ \\
\hline Rainfall & & \\
\hline $\begin{array}{l}\text { Evapotranspiration } \\
\text { Geomorphic features }\end{array}$ & DUFFY's + ROUTING & $\begin{array}{l}\text { Streamflow at any } \\
\text { river network node }\end{array}$ \\
\hline $\begin{array}{l}\text { Measured streamflow } \\
\text { Simulated streamflow }\end{array}$ & PARTICLE SWARMING & Model parameters \\
\hline $\begin{array}{l}\text { Measured streamflow } \\
\text { Simulated streamflow }\end{array}$ & VERIFICATION PACKAGE & Goodness of fit indices \\
\hline
\end{tabular}

several Hymods, one for each hillslope, instead of a single one for the whole catchment as is usual in literature, was twofold: firstly, to preserve the geometrical and topological structure of the river network, which proved to embed significant information about the shape of discharge hydrograph (D'Odorico and Rigon, 2003 and in reference therein); and secondly, to allow the use, as input, of spatially varying rainfall and evapotranspiration fields.

Hymod is based on the ideas presented in Moore (1985) and Bos and de Vreng (2006), and consists of two main parts: a non-linear component that partitions precipitation into precipitation excess, and two series of linear routing reservoirs that models quick and slow flow. The original model uses one linear reservoir that models the slow flow component, as we did, and a series of three identical linear reservoirs models the quick flow.

The conceptualization followed in Hymod considers a catchment in which water storage capacity is partially filled up with water (as in Fig. 1a) to $C_{\max }(L)$, the maximum water storage capacity. The water storage capacity between different points varies and it is assumed to be represented by the reflected power distribution function $F(C)$ :
$F(C)=1-\left(1-\frac{C}{C_{\max }}\right)^{B_{\exp }}$

in which $C(L), 0 \leq C \leq C_{\max }$, is the water storage capacity Moore (1985), $C_{\max }(L)$ is the maximum value of the water storage capacity of the basin and $B_{\text {exp }}$ accounts for the degree of spatial variability in the water storage capacities (as modeled in the Arno Todini (1996) model, which, however, uses a different mechanism for separating slow and quick flows).

The precipitation $P(L)$ that falls and exceeds $C_{\max }$ (as in Fig. 1b) directly flows, along the quick flow paths, into the river.

The precipitation that exceeds the water storage capacity, $C$ of points with a lower capacity than $C_{\max }$ (as in Fig. 1c) is instead divided into quick and slow flows according to a partition parameter Alpha (the Alpha part of it goes into the quick flow and the (1-Alpha) part goes into the slow flow).

Finally, some water evaporates according to the water stored in the slow reservoirs and the potential evapotranspiration, given by an external model. 

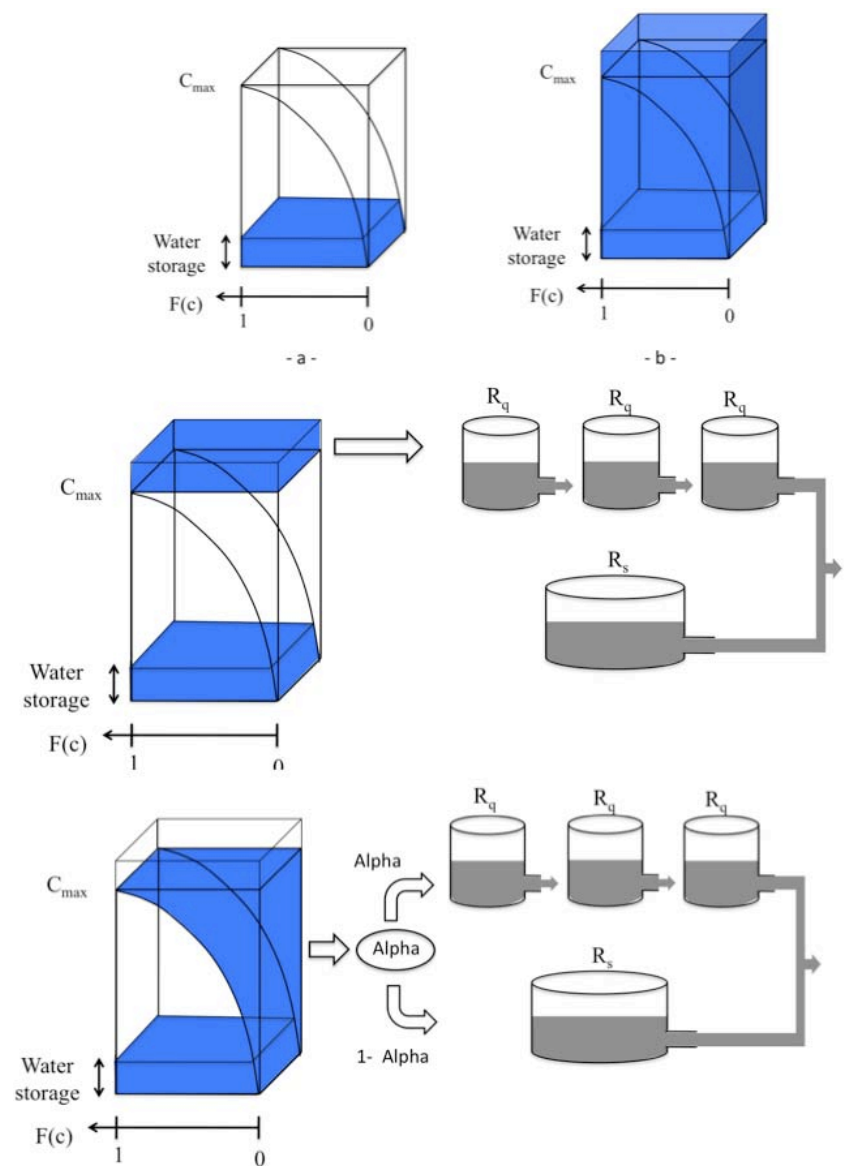

Fig. 1. Runoff generation in JGrass-NewAge System. (Top) On the left a representation of partially filled reservoirs; on the right the case of precipitation exceeding the storage capacity. (Center) When the total storage is exceeded, the precipitation excess is directly routed as overland flow by using three linear reservoirs. (Bottom) For precipitation not exceeding $C_{\max }$ the volume of precipitation above the curve is divided into overland flow and subsurface flow according to a coefficient of partition Alpha.

\subsection{Flow routing}

The flow generation model along hillslopes delivers discharge to the channel network, which in the model is conceptualized as an oriented tree graph, and is kinematically propagated downstream through a simplified model, derived from the CUENCAS model (Mantilla and Gupta, 2005), essentially a non linear variant of the Saint Venant equation (e.g. Bras and Rodríguez-Iturbe, 1994), integrated in each channel link.

The resulting system of equations allows an estimate of the varying discharge value in each link of the river network, with flow velocities varying with stage and positions. For each link the continuity equation, as presented in Mantilla et al. (2006), is in fact:

$$
\begin{array}{r}
\frac{d S_{i}(t)}{d t}=\left[Q_{\mathrm{gen}}(t)+\sum_{\text {trib }} Q_{\mathrm{trib}}(t)-Q_{i}(t)\right] \\
i=1,2, \ldots, H
\end{array}
$$

where is the $S_{i}(t)$ is storage in the $i$-th link at time $t, H$ is the total number of network links, $Q_{i}(t)\left(L^{3} T^{-1}\right)$ is the output discharge from $i$-th link, $Q_{\text {trib }}\left(\mathrm{L}^{3} \mathrm{~T}^{-1}\right)$ is the flow of upstream links, and $Q_{\mathrm{gen}}(t)\left(L^{3} T^{-1}\right)$ is the discharge generated at the hillslope of the link in question. Under the hypothesis that the link has a rectangular cross-section, so that the width, $w$, does not change in time, the channel storage and the discharge can be expressed as:

$S_{i}(t)=l_{i} \cdot w_{i} \cdot d_{i}(t)$

and:

$Q_{i}(t)=v_{i}(t) \cdot w_{i}(t) \cdot d_{i}(t)$

where $v_{i}(t)\left(L T^{-1}\right)$ is the flow velocity, $w_{i}(t)(L)$ is the mean width of the link, $d_{i}(t)(L)$ is the mean channel depth and $l_{t}(L)$ is the link length.

Combining the Eqs. (3) and (4) gives $S_{i}(t)$ in function of $Q_{i}(t)$; finally, using the Chezy equation:

$v=C \cdot R^{0.5} \cdot i_{\mathrm{b}}^{0.5}$

where $v\left(L T^{-1}\right)$ is the mean velocity, $C\left(L^{0.5} T^{-1}\right)$ is the Chezy coefficient, $R(L)$ is the hydraulic radius, and $i_{\mathrm{b}}(-)$ is the bottom slope, $S_{i}(t)$ can be expressed as:

$S(t)=Q(t)^{\frac{2}{3}} \cdot C^{-\frac{2}{3}} \cdot w^{\frac{1}{3}} \cdot l \cdot i_{\mathrm{b}}^{-\frac{1}{3}}$

The left hand side of the Eq. (2) is expressed by the derivative of the Eq. (6). After some algebra, Eq. (7) gives the nonlinear ordinary differential equation in the unknown $Q_{i}(t)$ :

$$
\begin{array}{r}
\frac{d Q_{i}(t)}{d t}=K\left(Q_{i}(t)\right) \cdot\left[Q_{\text {gen }}(t)+\sum_{\text {trib }} Q_{\text {trib }}(t)-Q_{i}(t)\right] \\
i=1,2, \ldots, H
\end{array}
$$

The coefficient $K\left(Q_{i}(t)\right)$ is equal to:

$K_{Q}=\frac{3}{2} \cdot Q^{\frac{1}{3}} \cdot C^{\frac{2}{3}} \cdot b^{-\frac{1}{3}} \cdot l^{-1} \cdot i_{\mathrm{b}}^{\frac{1}{3}}$

where $C\left(L^{1 / 3} T^{-1}\right)$ is the Chezy coefficient, $b(L)$ and $l(L)$ represent the width and average length of the link respectively, $i_{\mathrm{b}}(-)$ is the average slope of the link, and $Q\left(L^{3} T^{-1}\right)$ is the channel discharge. For a more detailed discussion of the terms in Eq. (8) see Menabde and Sivapalan (2001), and Mantilla and Gupta (2005) which provide also a description of how the parameters can be estimated by using geomorphic information. 


\subsection{Evapotranspiration}

Evapotranspiration was estimated by using the PriestleyTaylor (Priestley, 1959; Slatyer and McIlroy, 1961; Priestley and Taylor, 1972) modeling scheme. The Priestley-Taylor equation, (Eq. 10), proved to be effective and parsimonious (e.g. Beck, 1987; Wheater et al., 1993; Young and Beven, 1994), and suitable for use in continuous time rainfall runoff models. It reads:

$\lambda_{E} P E=\alpha^{\prime} \frac{\Delta}{\Delta+\gamma}\left(R_{n}-G\right)$

where $P E(L)$ is the potential evapotranspiration, $\lambda_{E}$ is the enthalpy of vaporization $\left(E M^{-1}\right)(E$ stands for energy units), $R_{n}\left(E L^{-2} T^{-1}\right)$ is net radiation at the terrain surface, as estimated by the CORRIPIO component; $G\left(E L^{-2} T^{-1}\right)$ is the heat conduction rate, $\Delta$ is the slope of the ClausiusClapeyron curve, which is provided in literature as function of the air temperature (Brutsaert, 1982), $\gamma$ is the psychometric constant $\left(M T^{-1}{ }^{\circ} \mathrm{K}\right)\left({ }^{\circ} \mathrm{K}\right.$ represent temperature units), and $\alpha^{\prime}$ is an empirical dimensionless coefficient.

The heat conduction rate $\mathrm{G}$ is related to the net radiation according to Allen (2005) and this reference relation is used in the model: $G=\beta R_{n}$ with $\beta \sim 0.1$ during the daytime and $\beta \sim 0.5 R_{n}$ during the nighttime. Therefore, in practice, the effective $P T$ equation used is:

$\lambda_{E} P E=\alpha^{\prime} \beta \frac{\Delta}{\Delta+\gamma} R_{n}$

Since, the goal of the present paper is just to give an estimate of discharge, which is a strongly aggregated information, the $\alpha^{\prime}$ coefficient is calibrated in order to obtain the overall mean annual evapotranspiration of the basin, as reported in literature.

\subsection{Parameters estimation}

An automatic mono-objective calibration of parameters remained free was used in this paper that can be split into two conceptual steps: the definition of the objective function, and the choice of the optimization algorithm. The objective function, which guides the optimization process, is the Kling-Gupta efficiency (KGE) function, which was obtained after convincing analysis in Gupta et al. (2009). According to the original paper, the whole calibration problem is viewed from a multi-objective perspective by focusing on three crucial aspects: (i) the correlation between simulated and observed values; (ii) relative variability in the simulated and observed values; and (iii) bias error. The equation used is:

$\mathrm{KGE}=1-E D$

where
$E D=\sqrt{(R-1)^{2}+(A-1)^{2}+(B-1)^{2}}$

in which $R$ represents the linear correlation coefficient between the simulated time series, $Q_{\mathrm{s}}$, and the observed one, $Q_{\mathrm{o}}$, A (Eq. 13) is the ratio between the observed $\left(\sigma_{\mathrm{o}}\right)$ and measured $\left(\sigma_{\mathrm{m}}\right)$ standard deviations of the time series and takes account of the relative variability:

$A=\frac{\sigma_{\mathrm{o}}}{\sigma_{\mathrm{m}}}$

$B$ (Eq. 14) takes account of the bias error.

$B=\frac{\mu_{\mathrm{s}}-\mu_{\mathrm{m}}}{\sigma_{\mathrm{m}}}$

where $\mu_{\mathrm{s}}$ and $\mu_{\mathrm{o}}$ are the means of simulated and measured time series. The KGE is able to provide an optimal solution which is simultaneously good for bias, flow variability and correlation. Apparently, as reported in Gupta et al. (2009), this is not achieved by using, for instance, the Nash-Sutcliffe efficiency (NSE) as objective function.

The optimization is performed using a classic "particle swarm" algorithm (Kennedy and Eberhart, 1995; Eberhart and Shi, 2001). The main concept behind the particle swarm population-based optimizer is inspired by social behavior and movement dynamics of insects, birds and fish. First a group of random "particles" (values of parameters) is randomly initialized and then, in order to find the global optimum of the objective function, each particle in the population adjusts its "flying" (i.e. change) according to its own flying experience and that of its companions. The flying experience, in turn, is determined by the flying velocities, i.e. the rate of change of their position in parameters space.

Suppose to draw $M$ particles in a $N$-dimensional search space, at the step $t$, the $i$-th particle of the swarm and its velocity are represented by the $N$-dimensional vectors respectively $\boldsymbol{X}_{i}^{t}=\left\{x_{i, 1}^{t}, x_{i, 2}^{t}, \ldots, x_{i, N}^{t}\right\}$ and $\boldsymbol{V}_{i}^{t}=\left\{v_{i, 1}^{t}, v_{i, 2}^{t}, \ldots, v_{i, N}^{t}\right\}$.

At each time step, the velocity and position of each particles (i.e. of the parameter set) are updated according to the equations:

$v_{i, n}^{t+1}=\omega \cdot v_{i, n}^{t}+c_{1} \cdot s_{1} \cdot\left(p_{i, n}^{t}-x_{i, n}^{t}\right)+c_{2} \cdot s_{2} \cdot\left(g_{n}^{t}-x_{i, n}^{t}\right)$

$x_{i}^{t+1}=x_{i}^{t}+v_{i}^{t+1}$

where $i=1,2, \ldots, D$, and $n=1,2, \ldots, N$, and in which:

- $p_{i}^{t}$ is the element of the vector $\boldsymbol{P}_{i}^{t}=\left\{p_{i, 1}^{t}, p_{i, 2}^{t}, \ldots, p_{i, N}^{t}\right\}$ representing the individual best position of the $i$-th particle (i.e. the best visited position of the i-th particle);

- $g_{n}^{t}$ is the element of the vector $\boldsymbol{G}^{t}=\left\{g_{1}^{t}, g_{2}^{t}, \ldots, g_{N}^{t}\right\}$ representing the best individual of the whole swarm. 
There are five parameters of the particle swarming algorithm: $s_{1}$ and $s_{2}$ are uniformly distributed random numbers between 0 and $1 ; c_{1}$, the so called self confidence factor, and $c_{2}$, the so called swarm confidence factor, are the acceleration constants ranging between 1.5 and 2; finally $\omega$ is an inertial factor usually ranging between 0.4 and 1.4. All these parameter value are set by the users at the beginning of the optimization process.

\subsection{Verification}

Even if the optimization itself guarantees optimal behavior of the calibrated discharge, this optimality is not usually maintained at the same level when forecasting is performed. Therefore, to quantitatively asses how well the modeled outputs fit the observed ones, several efficiency criteria have been presented and discussed in literature (Beven, 2001; Krause et al., 2005; Boyle et al., 2000).

In this paper, where the objective characterization of the forecasting capabilities of the system is paramount and which complements the subsequent discussion, three indices of goodness of fit were used: the root mean square error index (RMSE); the index of agreement, IOA, (Willmott et al., 1985); and the percentage model bias (PBIAS).

The mean square error index is a classic indicator that does not require further explanations. The IOA lies between 0 (no correlation) and 1 (perfect fit) and represents the ratio of the mean square error and the potential error (Willmott et al., 1985). As presented in Legates and McCabe Jr (1999), one of the advantage of this index is the sensitivity to extreme values owing to the squared differences.

The PBIAS measures the average tendency of the simulated flows to be larger or smaller than their observed values. The optimal PBIAS value is 0.0 , positive values indicate an overestimation of the model and negative values represent an underestimation. According to Marechal (2004) $\mid$ PBIAS $\mid<5$ indicates excellent model performance, $5<\mid$ PBIAS $\mid<10$ indicates very good model performance, with a $10<\mid$ PBIAS $\mid<20$ the model performance is good, while a $20<\mid$ PBIAS $\mid<40$ indicates that they are poor and, finally, a $|\mathrm{PBIAS}|>40$ indicates very poor model performance.

This useful index is able to summarize whether the model is systematically underestimating or overestimating the observations.

\section{An application to Little Washita (OK, USA) river basin}

To test the capabilities of the JGrass-NewAge system, we applied it to the Little Washita river basin $\left(611 \mathrm{~km}^{2}\right)$, (Fig. 2), located in southwestern Oklahoma, between Chickasha and Lawton. The choice was determined by the presence of good and complete datasets of meteorological forcings,
Table 2. List of the meteorological stations used in the simulations performed.

\begin{tabular}{llllr}
\hline ID & City & LAT. & LONG. & $\begin{array}{r}\text { Elevation } \\
(\mathrm{m})\end{array}$ \\
\hline 121 & Ninnekah & 34.9586 & -97.8986 & 343.0 \\
124 & Norge & 34.9728 & -98.0581 & 387.0 \\
131 & Cyril & 34.9503 & -98.2336 & 458.0 \\
132 & Cement & 34.9428 & -98.1819 & 456.0 \\
133 & Cement & 34.9492 & -98.1281 & 430.0 \\
134 & Cement & 34.9367 & -98.0753 & 384.0 \\
135 & Cement & 34.9272 & -98.0197 & 366.0 \\
136 & Ninnekah & 34.9278 & -97.9656 & 343.0 \\
144 & Agawam & 34.8789 & -97.9172 & 388.0 \\
146 & Agawam & 34.8853 & -98.0231 & 358.0 \\
148 & Cement & 34.8992 & -98.1281 & 431.0 \\
149 & Cyril & 34.8983 & -98.1808 & 420.0 \\
150 & Cyril & 34.9061 & -98.2511 & 431.0 \\
152 & Fletcher & 34.8611 & -98.2511 & 416.0 \\
153 & Cyril & 34.8553 & -98.2 & 414.0 \\
154 & Cyril & 34.8553 & -98.1369 & 393.0 \\
156 & Agawam & 34.8431 & -97.9583 & 397.0 \\
159 & Rush Springs & 34.7967 & -97.9933 & 439.0 \\
162 & Sterling & 34.8075 & -98.1414 & 405.0 \\
182 & Cement & 34.845 & -98.0731 & 370.0 \\
\hline & & & &
\end{tabular}

as provided by the USDA Agricultural Research Service (http://www.ars.usda.gov/Main/docs.htm?docid=8739), and by the absence of relevant snowfall and soil freezing, which is not modeled by the assembly of components used in the specific case.

The climate of the basin can be characterized as moist and sub-humid with a long-term, spatially average, annual precipitation of $760 \mathrm{~mm}$ and a temperature of 16 degrees Celsius; winters are typically short, temperate, and dry but are usually very cold for a few weeks. Summers are typically long, hot, and relatively dry The elevation of the basin ranges between about $300 \mathrm{~m}$ and about $500 \mathrm{~m}$ a.s.1. The bedrock exposed in the watershed consists of Permian age sedimentary rocks and soil textures range from ne sand to silty loam.

The meteorological stations considered in this application are plotted in black dots in Fig. (2) and the hydrometer where the calibration is performed is depicted with a black triangle.

Table 2 reports the main information (coordinates, and elevations) of the twenty meteorological stations (whose data are available at http://ars.mesonet.org/). Five minute measurements of rainfall $(P)$, air temperature $(T)$, and incoming solar radiation $(R)$ were cumulated to hourly time steps and used as input of the modeling system.

The hydrometer measures discharge at $15 \mathrm{~min}$ resolution (http://waterdata.usgs.gov/nwis); they were cumulated to hourly time step and used in the automatic calibration procedure. 


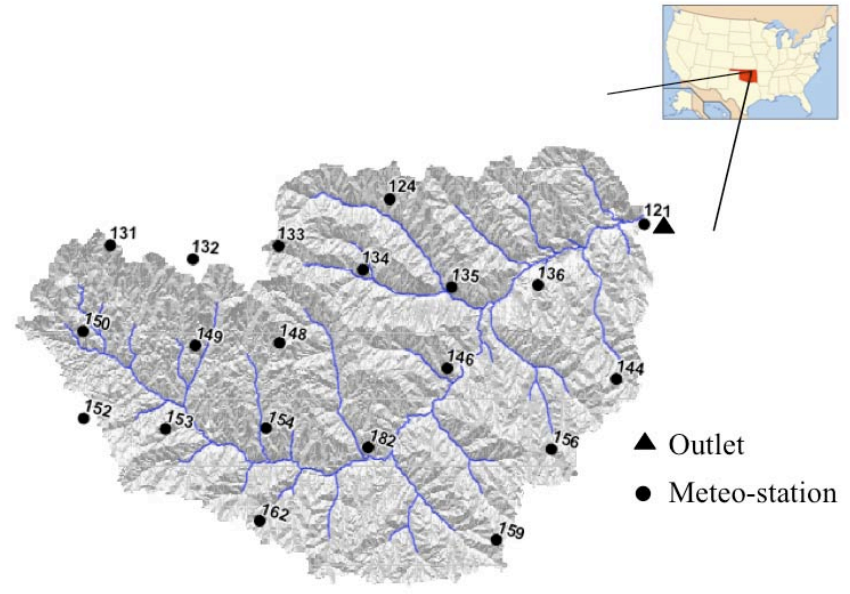

Fig. 2. The Little Washita river basin, Oklahoma (USA).

Two applications are presented in this work. In the first (Test A) an application of the runoff generation component Hymod is made for the basin as a whole; the input precipitation time series is the spatial mean of all the measurements and the evaporation time series represents the global mean potential evapotranspiration. This configuration can be seen as the null hypothesis against which to test the other modeling set-ups.

In the second application (Test B) the Little Washita river basin is split into 75 sub-basins and a different Hymod model is run for each of them, with its own estimate of evapotranspiration and rainfall (preserving, however, the total volumes of the quantities for comparison with the lumped case).

Furthermore, the generated discharge of each hillslope is routed applying the scheme where the parameters were evaluated according to the network geomorphology Mantilla and Gupta (2005).

In both Test A and Test B the automatic calibration was performed at the outlet of the basin and the simulation period ranged from 1 January 2002 to 31 December 2003. The first year was used for the calibration, while the second year was used for the validation of the results.

The number of "particles" used in the calibration process was 50 and the algorithm parameter values were set according to literature hints (Eberhart and Shi, 2001) as: $\omega=0.6$, $c_{1}=1.8, c_{2}=2.0, s_{1}$ and $s_{2}$ randomly distributed between 0 and 1.

Table 3 shows the parameter values obtained by the calibration component for Test A and Test B respectively. The top line of Table 4 shows the values of the test of fit obtained by the calibration for the Test A and the bottom line of Table 4 shows the values of test of fit of Test $B$.

The simulation results of Test A and Test B are presented in Figs. 7 and 8 in which the gray dots represent the measured discharge and the black solid line represents the simulated discharge, all of which will be commented in the next section.
Table 3. Parameter values used in simulation.

\begin{tabular}{lcccrr}
\hline & $C_{\max }$ & $B_{\exp }$ & $\alpha$ & $R_{\mathrm{S}}$ & $R_{q}$ \\
\hline Test A & 603.45 & 0.31 & 0.35 & 0.0098 & 0.13 \\
Test B & 572.52 & 0.85 & 0.39 & 0.001 & 0.12 \\
\hline
\end{tabular}

Table 4. Index of goodness of fit for calibration and validation period.

\begin{tabular}{ccccc}
\hline & & IOA & RMSE & PBIAS \\
\hline Test A & Calibration & 0.76 & 0.96 & 18.7 \\
Test A & Validation & 0.71 & 1.06 & 24.8 \\
\hline Test B & Calibration & 0.88 & 0.76 & 3.5 \\
Test B & Validation & 0.81 & 0.80 & 5.8 \\
\hline
\end{tabular}

\section{Results}

The visual inspection of simulated hydrographs provided by Test A and Test B show an acceptable agreement with the measured one, although an apparent tendency towards under prediction of flow peak values is evident in both Test $\mathrm{A}$ and Test B, even though it is more accentuated in Test A. While the largest peaks are usually underestimated, the secondary peak flows are sometimes overestimated. The underestimation for the largest peak is around the $0.32 \%$ in the case of Test $\mathrm{A}$ and around the $0.10 \%$ in the case of Test B. To make this more clear, single events where the same behavior is evident are plotted in Figs. 4 and 4. For the limited case of these events the indices of goodness are reported in Table 5. The recession curves are usually well reproduced with an apparent tendency to underestimation.

The values of all three indices of goodness confirm the idea that came from the visual inspection. In fact, in Test B all the values are significantly better performing than Test A. It can be observed that the values of the parameters obtained for the test case are similar, with better performances for the Test B, greater than $10 \%$ for IOA and $20 \%$ for the RMSE. However, the the PBIAS greatly discriminates the better performances of Test B, since Test B has a very good performance, and Test A, just a good one. Therefore, all the indices tests suggest that using the spatial information available (and the increased complexity of the distributed model) is useful to get a significantly better forecasting, at least for the case presented. The result is much more significant since both Test A and Test B were obtained, not only with equal meteorological forcings, but with the forcings treated by the same code components plugged with the core model assembly at run-time. 
Event n.1: Test A

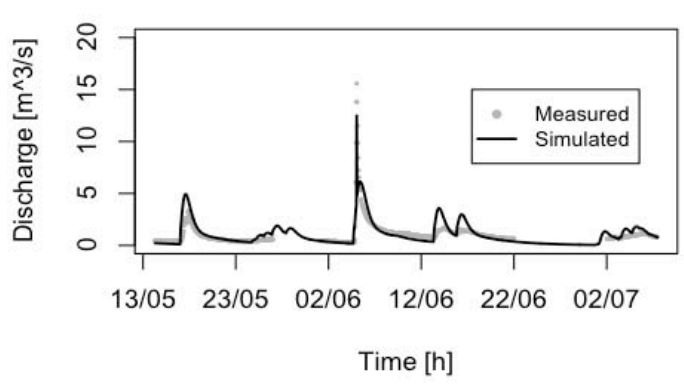

Event n.1: Test B

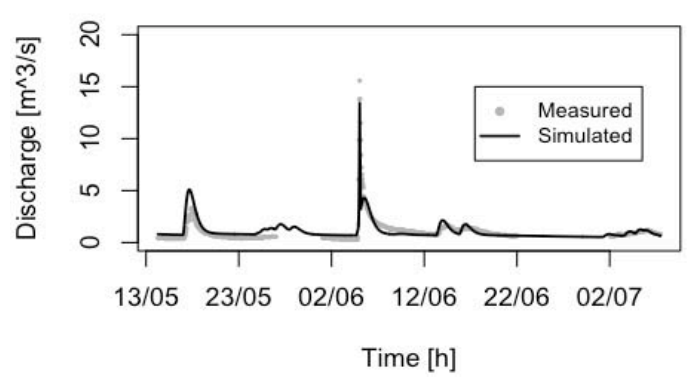

Fig. 3. Event No. 1: test case A at the top and test case B at the bottom. The year of the events registered is 2003 .
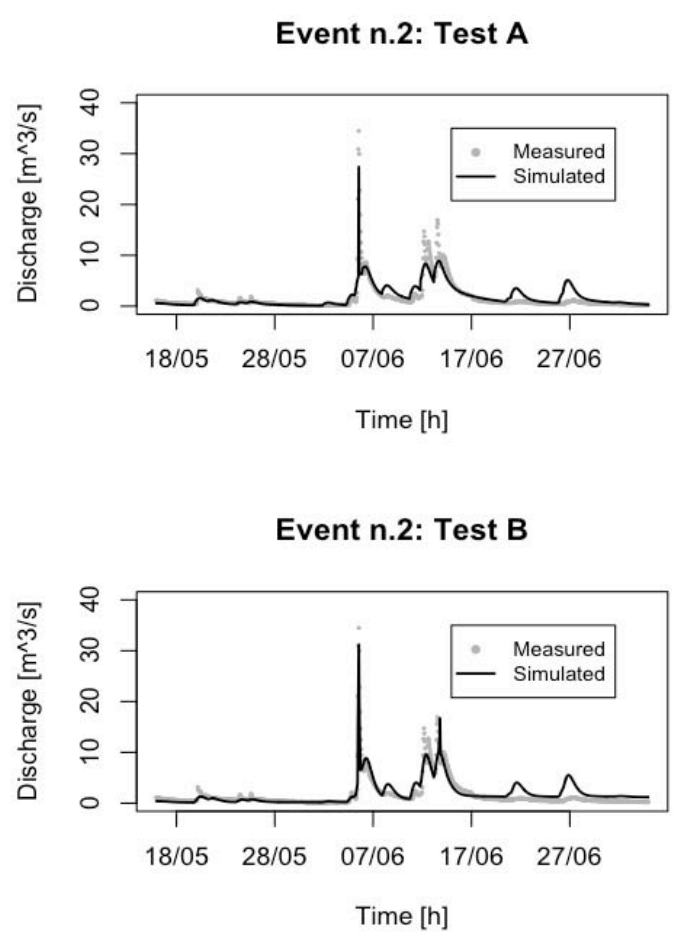

Fig. 4. Event No. 2: test case A at the top and test case B at the bottom.
Test B: Residuals plot

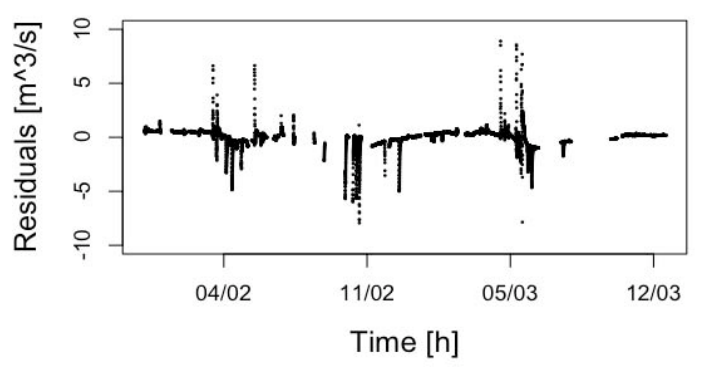

Fig. 5. Test B: plot of the residuals for the validation period. Large values are usually due to time shifts between the measured and simulated discharge.

\section{Test B: Residuals histogram}

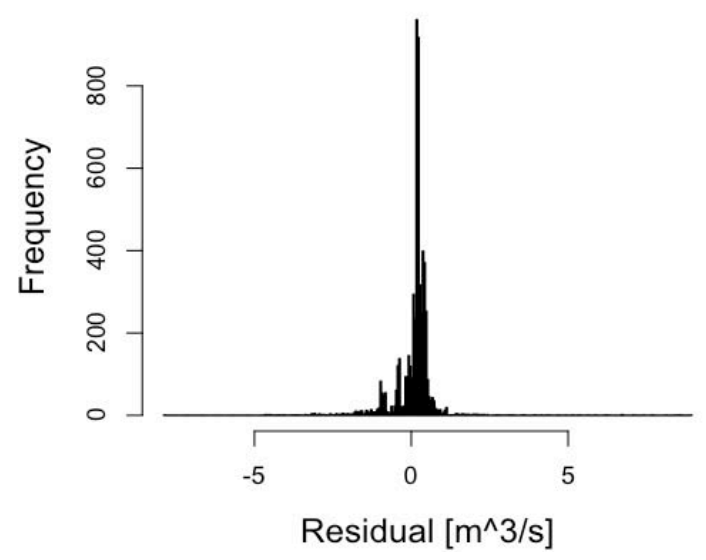

Fig. 6. Test B: histogram of the residuals of the simulated discharge with respect to the measured ones.

The plot of residuals, just for test case B, in Fig. 5, gives a different view of the errors. They could be seen as large as ten cubic meter per second, which is quite a large fraction of the peak discharge, and larger than the differences of the peaks of corresponding events because the simulated and measured peaks are recorded at slightly different times; therefore, when the simulated peak arrives the measured discharge is already in the recession limb. The analysis of the histogram of the residuals presented in Fig. 6 for the validation period shows an almost normal distribution of the residual with mean close to zero $\left(0.0102 \mathrm{~m}^{3} \mathrm{~s}^{-1}\right)$ and standard deviation less then of $0.71 \mathrm{~m}^{3} \mathrm{~s}^{-1}$. The low value of the bias confirms the goodness of the calibration procedure and the goodness of the model assembly with respect of the simulations of the hydrological behavior of the basin analyzed.

Estimations of inner values of the discharge in the basin have been provided in Fig. 9 in order to visualize this capability of the model. However, these estimations cannot be controlled against measured data and have only a demonstration 
Discharge hourly simulation: 2002/01/01-2003/31/12

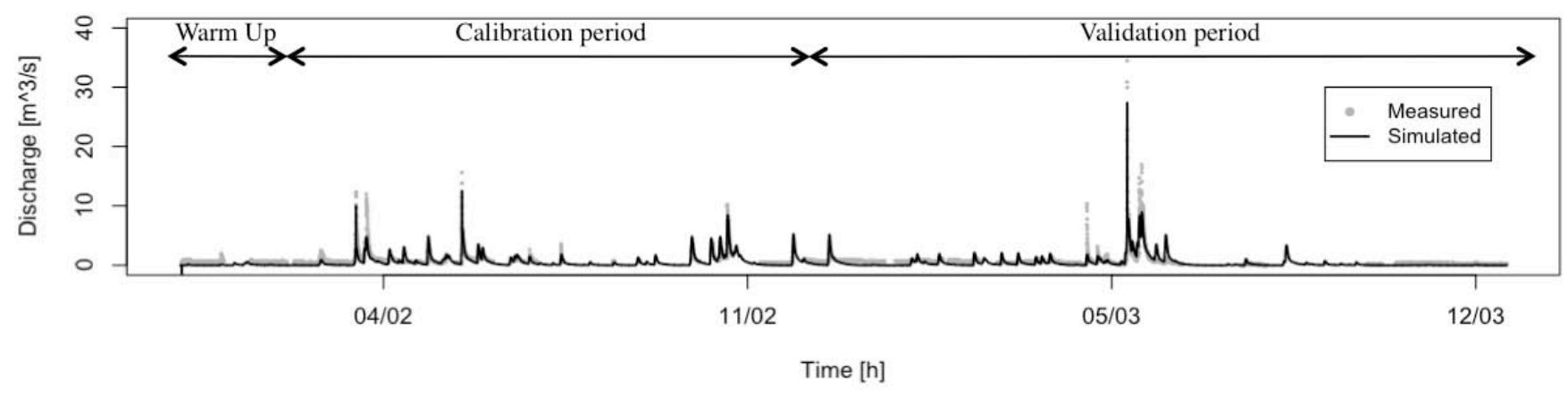

Fig. 7. Test A: application of the JGrass-NewAge model for the period 01/01/2002 to 31/12/2003: the solid curve represents the simulated discharge, while the dots represents the measured one.

Discharge hourly simulation: 2002/01/01-2003/31/12

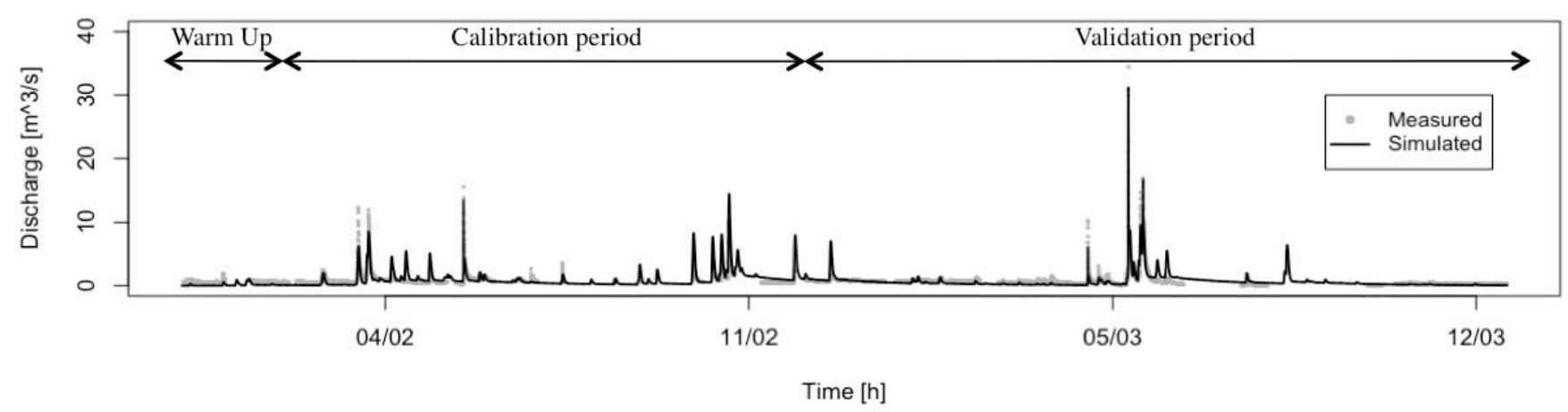

Fig. 8. Test B: application of the JGrass-NewAge model for the period 01/01/2002 to 31/12/2003: the solid curve represents the simulated discharge, while the dots represents the measured one.

Table 5. Test B: indices of goodness of fit for the calibration and validation periods.

\begin{tabular}{lcc}
\hline & IOA & NSE \\
\hline Event n. 1: Test A & 0.86 & 0.50 \\
Event n. 1: Test B & 0.92 & 0.64 \\
\hline Event n. 2: Test A & 0.93 & 0.78 \\
Event n. 2: Test B & 0.87 & 0.65 \\
\hline
\end{tabular}

value. What is visible from the figure, besides the evident decrease of discharge with contributing areas which can be shown to be closely linear for major events where the precipitation affects the whole catchment, is that in minor events the local distribution of rainfall can produce uneven behaviors.

In many cases the error in forecasting is small and, even if more accurate studies of this aspect should be necessary, it can be said that they are contained within an interval of confidence depending on the uncertainty (e.g. Vrugt et al., 2008) that can be introduced by erroneous estimation of local precipitation and of the relation between the stage (which is what is actually measured) and discharge.

\section{Conclusions}

The novel idea behind the JGrass-NewAge system is to provide not only a new hydrological tool but an informatics infrastructure in which any model can be built in components that can be independently modified or changed, and which seamlessly work in a GIS environment (through the udig Spatial Toolboox), once programmed as the Object Modelling System v3 requires.

The system allows for comparison of single parts of a modelling chain, keeping the others fixed, thus making the localization of errors and the testing of alternatives altogether easier. This was shown, in the present case, by comparing the 

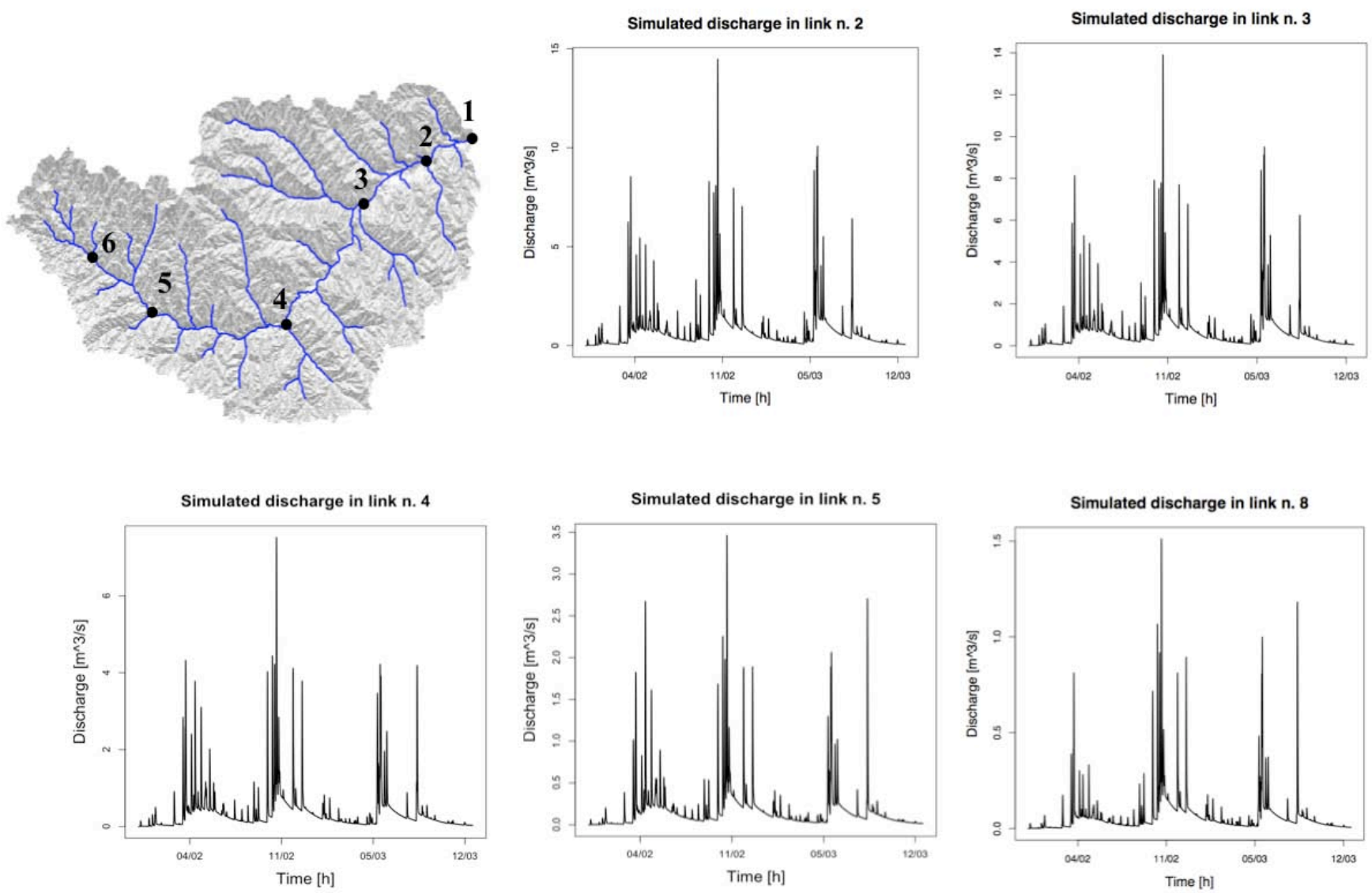

Fig. 9. Application of the JGrass-NewAge model for the period 01/01/2002 to 31/12/2003.

case of two submodels for runoff production, one of which, whilst appealing from a theoretical point of view, revealed unfeasible during calibration. This models was, in fact, easily substituted by another without the need to rebuild the whole model system.

The versatility of the modeling approach was also tested by implementing two different modeling chains, one substantially performing simulation with a very lumped application of the model, just using Hymod for the whole catchment, the other representing a more distributed "version" of the same Hymod runoff generating mechanism, connected with a routing scheme. The forecasts were tested by analysis of the residuals and through the estimation of some objective indices, which were also implemented as software components. These allowed us to objectively state that, at least for the case in study, the performances of the distributed version of the modeling chain was significantly better than the lumped version, thus supporting the idea that the increase in model complexity was worthwhile. It is noteworthy that this comparison was made between systems where most of the code was the same, thus guaranteeing, in our opinion, the most fair comparison possible.
The modeling chain, although seemingly very traditional, was actually implemented using advanced specifications of the geographical objects, as required by OGC, and uses a particular specification of the river network hierarchy and the related hillslopes that was built upon the Pfafstetter ordering scheme.

Even though the overall performances of the forecasting can be considered very good, in the future some new components could substitute the older ones and be compared consistently along the same lines, even if further improvements in the ability to forecast measured discharge could not be considered significant without a proper assessment of the uncertainties inherent to the description of the processes.

These comparisons could be made by the same authors or independently by other researchers, since the JGrassNewAge modeling system is freely available, with just the new component requiring coding. In this sense the infrastructure promotes independent testing and verification of research results with unprecedented easiness. In this perspective a component by component and interoperability comparison of the JGrass-NewAge system with others, such as PRSM (Leavesley et al., 1983) or J2000 (Krause, 2001) that embraced the OMS3 frameworks can be envisaged. 
Acknowledgements. This project was partially financed by the MORFEO project, financed by the Italian Space Agency, and the Hydrolp project, financed by the Province of Bolzano that supported one of the authors, and the project Adige, financed by the River Adige Autority, that supported most of the informatics development. The Authors are grateful to Professor Peter Krause, Kumar Surprit and Sudeep Samanta who reviewed the manuscript and helped with their observations in improving the final version. The model components presented are under the process of quality code review and are to be made freely available under the GPL v3 license at the site http://www.jgrasstools.org.

Edited by: M. T. Coe

\section{References}

Allen, R.: The ASCE standardized reference evapotranspiration equation, Am. Soc. Civil Eng., 2005.

Antonello, A., Franceschi, S., Formetta, G., and Rigon, R.: The JGrass-NewAge System for Forecasting and Managing the Hydrological Budgets at the Basin Scale: the informatic structure, Geosci. Model. Dev. Discuss., in preparation, 2011.

Beck, M.: Water quality modeling: a review of the analysis of uncertainty, Water Resour. Res., 23, 1393-1442, 1987.

Beven, K.: Rainfall-runoff modelling: the primer, John Wiley \& Sons Inc, 2001.

Beven, K. and Kirkby, M.: A physically based, variable contributing area model of basin hydrology/Un modèle à base physique de zone d'appel variable de l'hydrologie du bassin versant, Hydrol. Sci. J., 24, 43-69, 1979.

Bos, A. and de Vreng, A.: Parameter optimization of the HYMOD model using SCEM-UA and MOSCEM-UA, Modelling GeoEcological Systems Computational Bio-and Physical Geography. University of Amsterdam, 43 pp., 2006.

Boyle, D. P.: Multicriteria calibration of hydrological model, Ph.D. dissertation, Dep. of Hydrol. and Water Resour., Univ. of Ariz., Tucson, 2001.

Boyle, D. P., Gupta, H., and Sorooshian, S.: Toward improved calibration of hydrologic models: Combining the strengths of manual and automatic methods, Water Resour. Res., 36, 3663-3674, 2000.

Bras, R. and Rodríguez-Iturbe, I.: Random functions and hydrology, Dover Pubns, 1994.

Brutsaert, W.: On a derivable formula for long-wave radiation from clear skies, Water Resour. Res., 11, 742-744, 1975.

Brutsaert, W.: Evaporation into the atmosphere: Theory, history, and applications, vol. 1, Springer, 1982.

Brutsaert, W.: Hydrology: an introduction, Cambridge Univ. Press, 2005.

Burnash, R., Ferral, R., and McGuire, R.: A generalized streamflow simulation system - Conceptual modeling for digital computers, report, Joint Fed. and State River Forecast Cent, US Natl. Weather Serv./Calif. State Dept. of Water Resour., Sacramento, Calif., 1973.

Corripio, J.: Vectorial algebra algorithms for calculating terrain parameters from DEMs and solar radiation modelling in mountainous terrain, Int. J. Geogr. Inf. Sci., 17, 1-24, 2003.

Crawford, N. and Linsley, R.: Digital simulation in hydrology: Stanford watershed model IV, vol. 1966, Dept. of Civil Engi- neering, Stanford University, 1966.

David, O., Ascough, J., Leavesley, G., and Ahuja, L.: Rethinking modeling framework design: object modeling system 3.0, in: Environmental Modeling International Conference Proceedings, 58, 2010.

de Jager, A. and Vogt, J.: Development and demonstration of a structured hydrological feature coding system for Europe, Hydrol. Sci. J., 55, 661-675, 2010.

Dietrich, W. E., Wilson, C. J., Montgomery, D. R., McKean, J., and Bauer, R.: Erosion thresholds and land surface morphology, Geology, 20, 675-679, doi:10.1130/00917613(1992)020;0675:ETALSM;2.3.CO;2, 1992.

D'Odorico, P. and Rigon, R.: Hillslope and channel contributions to the hydrologic response, Water Resour. Res., 39, doi:10.1029/2002WR001708, 2003.

Dooge, J.: A general theory of the unit hydrograph, J. Geophys. Res, 64, 241-256, 1959.

Duffy, C. J.: A Two-State Integral-Balance Model for Soil Moisture and Groundwater Dynamics in Complex Terrain, Water Resour. Res., 32, 2421-2434, doi:10.1029/96WR01049, 1996.

Eberhart, R. and Shi, Y.: Particle swarm optimization: developments, applications and resources, in: Proceedings of the 2001 congress on evolutionary computation, Piscataway, NJ, USA: IEEE, vol. 1, 81-86, 2001.

Flügel, W.: Delineating hydrological response units by geographical information system analyses for regional hydrological modelling using PRMS/MMS in the drainage basin of the River Bröl, Germany, Hydrol. Process., 9, 423-436, 1995.

Franchini, M., Wendling, J., Obled, C., and Todini, E.: Physical interpretation and sensitivity analysis of the TOPMODEL, J. Hydrol., 175, 293-338, 1996.

Garen, D. and Marks, D.: Spatially distributed energy balance snowmelt modelling in a mountainous river basin: estimation of meteorological inputs and verification of model results, J. Hydrol., 315, 126-153, 2005.

Goovaerts, P.: Geostatistics for natural resources evaluation, Oxford University Press, USA, 1997.

Gupta, H., Kling, H., Yilmaz, K., and Martinez, G.: Decomposition of the mean squared error and NSE performance criteria: Implications for improving hydrological modelling, J. Hydrol., 377, 80-91, 2009.

Gupta, V. and Waymire, C.: A representation of an instantaneous unit hydrograph from geomorphology, Water Resour. Res., 16, 855-862, 1980.

Jarvis, C. and Stuart, N.: A comparison among strategies for interpolating maximum and minimum daily air temperatures. Part I: The selection of "guiding"topographic and land cover variables, J. Appl. Meteorol., 40, 1060-1074, 2001.

Kampf, S. K. and Burges, S. J.: A framework for classifying and comparing distributed hillslope and catchment hydrologic models, Water Resour. Res., 43, doi:10.1029/2006WR005370, 2007.

Kennedy, J. and Eberhart, R.: Particle swarm optimization, in: Neural Networks, 1995, Proceedings., IEEE International Conference on, IEEE, vol. 4, 1942-1948, 1995.

Krause, P.: Das hydrologische Modellsystem J2000: Beschreibung und Anwendung in großen Flußgebieten, Forschungszentrum, Zentralbibliothek, 2001.

Krause, P.: Quantifying the impact of land use changes on the water balance of large catchments using the J2000 model, Phys. Chem. 
Earth, Parts A/B/C, 27, 663-673, 2002.

Krause, P., Boyle, D. P., and Bäse, F.: Comparison of different efficiency criteria for hydrological model assessment, Adv. Geosci., 5, 89-97, doi:10.5194/adgeo-5-89-2005, 2005.

Leavesley, G., Lichty, R., Troutman, B., and Saindon, L.: Precipitation-runoff modeling system: User's manual, Available from Books and Open File Report Section, USGS Box 25425, Denver, Co 80225, USGS Water Resources Investigations Report 83-4238, 1983, 207 pp., 54 fig, 15 tab, 51 ref, 8 attach., 1983.

Legates, D. and McCabe Jr., G.: Evaluating the use of "goodnessof-fit" measures in hydrologic and hydroclimatic model validation, Water Resour. Res., 35, 233-241, 1999.

Mantilla, R. and Gupta, V.: A GIS numerical framework to study the process basis of scaling statistics in river networks, IEEE Geosci. Remote Sens. Lett., 2, 404-408, 2005.

Mantilla, R., Gupta, V. K., and Mesa, O. J.: Role of coupled flow dynamics and real network structures on Hortonian scaling of peak flows, J. Hydrol., 322, 155-167, doi:10.1016/j.jhydrol.2005.03.022, 2006.

Marechal, D.: A soil-based approach to rainfall-runoff modelling in ungauged catchments for England and Wales, 2004.

Menabde, M. and Sivapalan, M.: Linking space-time variability of river runoff and rainfall fields: a dynamic approach, Adv. Water Res., 24, 1001-1014, 2001.

Montgomery, D. and Dietrich, W.: A physically based model for the topographic control on shallow landsliding, Water Resour. Res., 30, 1153-1171, 1994.

Moore, R. J.: The probability-distributed principle and runoff production at point and basin scales, Hydrol. Sci. J., 30, 273-297, doi:10.1080/02626668509490989, 1985.

Mulvaney, T.: On the Use of Self-Registering Rain and Flood Gauges in Making Observations of the Relations of Rainfall and of Flood Discharges in a Given Catchment, Transactions and Minutes of the Proceeding of the Institute of Civil Engineers of Ireland, 1851.

Pirotti, F. and Tarolli, P.: Suitability of LiDAR point density and derived landform curvature maps for channel network extraction, Hydrol. Process., 24, 1187-1197, 2010.

Priestley, C.: Turbulent transfer in the lower atmosphere, University of Chicago Press Chicago, Ill., 1959.

Priestley, C. and Taylor, R.: On the assessment of surface heat flux and evaporation using large-scale parameters, Mon. Weather Rev., 100, 81-92, 1972.

Reed, S., Koren, V., Smith, M., Zhang, Z., Moreda, F., Seo, D., and DMIP, P.: Overall distributed model intercomparison project results, J. Hydrol., 298, 27-60, 2004.

Rigon, R., Bertoldi, G., and Over, T.: GEOtop: A distributed hydrological model with coupled water and energy budgets, J. Hydrometeorol., 7, 371-388, 2006.
Rigon, R., D’Odorico, P., and Bertoldi, G.: The geomorphic structure of the runoff peak, Hydrol. Earth Syst. Sci., 15, 1853-1863, doi:10.5194/hess-15-1853-2011, 2011.

Rinaldo, A., Marani, A., and Rigon, R.: Geomorphological dispersion, Water Resour. Res., 27, 513-525, doi:10.1029/90WR02501, 1991.

Rodriguez-Iturbe, I. and Rinaldo, A.: Fractal river networks: chance and self-organization, 1997.

Rodríguez-Iturbe, I. and Valdés, J.: The geomorphologic structure of hydrologic response, Water Resour. Res., 15, 1409-1420, 1979.

Ross, B., Contractor, D., and Shanholtz, V.: A finite-element model of overland and channel flow for assessing the hydrologic impact of land-use change, J. Hydrol., 41, 11-30, 1979.

Rosso, R.: Nash model relation to Horton order ratios, Water Resour. Res., 20, 914-920, 1984.

Sherman, L.: Streamflow from rainfall by the unit-graph method, Eng. News Record, 108, 501-505, 1932.

Sivapalan, M., Blöschl, G., Zhang, L., and Vertessy, R.: Downward approach to hydrological prediction, Hydrol. Process., 17, 21012111, 2003.

Slatyer, R. and McIlroy, I.: Practical microclimatology: with special reference to the water factor in soil-plant-atmosphere relationships, UNESCO, 1961.

Todini, E.: The ARNO rainfall-runoff model, J. Hydrol., 175, 339382, 1996.

Verdin, K. and Verdin, J.: A topological system for delineation and codification of the Earth's river basins, J. Hydrol., 218, 1-12, 1999.

Viviroli, D., Zappa, M., Gurtz, J., and Weingartner, R.: An introduction to the hydrological modelling system PREVAH and its pre-and post-processing-tools, Environ. Model. Softw., 24, 1209-1222, 2009.

Vrugt, J. A., ter Braak, C. J. F., Clark, M. P., Hyman, J. M., and Robinson, B. A.: Treatment of input uncertainty in hydrologic modeling: Doing hydrology backward with Markov chain Monte Carlo simulation, Water Resour. Res., 44, doi:10.1029/2007WR006720, 2008.

Wheater, H., Jakeman, A., and Beven, K.: Progress and directions in rainfall-runoff modelling, 1993.

Willmott, C., Ackleson, S., Davis, R., Feddema, J., Klink, K., Legates, D., O'Donnell, J., and Rowe, C.: Statistics for the evaluation and comparison of models, J. Geophys. Res., 90, 89959005, 1985.

Young, P. and Beven, K.: Data-based mechanistic modelling and the rainfall-flow non-linearity, Environmetrics, 5, 335-363, 1994. 